Juanita Gallardo. Déjame que te cuente Santiago deChile: Planeta, 1999. Colección M emoria deChile; 251 pp.

Sara Almarza*

O ES RARO que nuestros países de América Latina hayan alzado a sus héroes sin prestar atención a la totalidad de la persona. Tal vez la necesidad urgente que tuvieron las élites en realzar paradigmas que unieran al pueblo llevó a que la vida privada, entiéndase la familiar, no tuviera espacio dentro del realce que se les daba como figuras ejemplares. Sin duda pueden haber excepciones.

A continuación me refiero a la figura de Bernardo O'Higgins, nuestro héroe chileno de origen irlandés, cuya vida la conocemos a través de la historia oficial. A través del tiempo, nos han dado a conocer aspectos que atañían al ejército o asuntos que interesaban a algunos historiadores, dejando de lado cualquier situación que lo mostrasen como un ser humano inserto en su tiempo histórico y social. Por eso es tan atrayente todo complemento a la biografía de un hombre de quien tanto se ha hablado. Dos características presenta la novela quevoy a comentar - completa la biografía y desmitifica a la persona. Me refiero a Déjame quete cuente (Santiago, Planeta, 1999), de Juanita Gallardo, texto que se lee de una sola sentada, como recomienda Edgar A. Poe.

Nosotros, no pareciendo lectores del siglo veintiuno, al adentrarnos a esa mezcla de hechos verídicos y realidad imaginaria, nos dejamos llevar por el chisme. Sin embargo, los resabios positivistas nos inclinan a confrontar, en la misma novela, los diferentes rumores que rodearon la vida de O'H iggins - que algunos chilenos ya sabíamos- con los documentos escritos. Estamos frente a una ficción histórica pero que delata sus fuentes. La autora aclara la forma de tejer el texto y con qué documentos históricos lo ha alimentado, ya que ofrece, al final, la bibliografía utilizada. Así va hilvanándose este relato.

\footnotetext{
*Universidad de Brasilia, Brasil.E-mail: salmarza@unb.br
} 
La trama está urdida con "las mentiras de la autora y las mentiras de otros". De estemodo se refiere a los innumerables escritos de diversos historiadores sobre la vida del chillanejo, donde cada quien tiene su propia interpretación. En tal sentido, es pertinente recordar la diferencia que existe entre el historiador de hoy y sus colegas de antaño en relación a entender que cuando se lidia con hechos del pasado y se intenta representarlos, dicha representación está impregnada con las nociones, valores e intereses de clase de cada uno. Los hechos no hablan por sí mismos, es el historiador y el novelista que platica por ellos.

Las más de doscientas páginas prenden la atención desde las primeras líneas cuando nos enteramos que tal vez podríamos haber tenido una "madre de la Patria", si no fuera porque Rosario Puga se casó tan sumamente joven y dejó a su marido en una época en queesa actitud era inaceptable. La novela trata, pues, de la gran omisión por parte de la historia oficial de la existencia de la madre-Rosario Puga- del único hijo de O'H iggins, llamado Demetrio Puga cuando niño, Demetrio Jara cuando su padre se lo lleva a vivir a Perú y, por último, Demetrio O'Higgins cuando nuestro prócer le lega por testamento su apellido. Se repite la misma situación que el propio Bernardo tuvo que sufrir y el mismo rechazo social de ser considerado un huacho, palabra injuriosa y despectiva, desde la época colonial, para designar a los hijos engendrados fuera del matrimonio civil.

Dentro de los varios asuntos, conflictos e informaciones que nos comunica esta novela, destaco el tema del hijo bastardo. M e pareceque este aspecto atraviesa los diversos grupos sociales y es preocupación de diferentes personajes en ese espacio ficticio. Tal vez podríamos afirmar que se trata deuna lamentable "tradición" familiar como afirma uno de ellos. Con estas palabras, le comenta Federico Puga, también hijo de Rosario a su medio hermano Demetrio O'H iggins, la inclinación de la familia por poblar nuestra tierra de hijos huachos. Y no deja de tener razón, pues la tradición de engendrar bastardos se repite con Demetrio y éste la repite con su hija Antonia, "su huachita" del Perú, como se dice en el texto, situación que le dolía enormemente y que sólo logra tranquilizarse pensando que "por suerte era una niña". Con el tiempo, Demetrio, ya cincuentón, se enamora de verdad, pero de una joven de catorce años, la que muere al dar a luz. Sin embargo le sobrevive la hija, a la que bautizan como Carmen Demetria O'Higgins. ¿Se rompió la tradición? ¿La niña ya no es más una bastarda por llevar el apellido? Claro queno, pues continúa siendo una huacha a los ojos dela sociedad y, sobre todo, porque la niña crecerá con la ausencia del padre, ya que Demetrio acaba con su vida - como se deja entrever en la novela- días después de la muerte de su amada. En relación a este asunto, vale recordar que la sociedad chilena tuvo que aguantar el oprobio de los huachos, bastardos o ilegítimos hasta el fin del siglo veintecuando en 1998 se deroga, antela ley, tal desigualdad. 
En el entorno familiar de $\mathrm{O}$ 'H iggins y en la novela que comento, el tema de los hijos huachos, de suma importancia en la realidad latinoamericana que, a su vez, se relaciona con una amplia problemática como es la identidad, no termina con las nietas de Bernardo O'Higgins. También la historia ha callado la existencia de Nieves Rodríguez Riquelme, la hermana menor de Bernardo por parte de madre. Y el círculo se estrecha cuando sabemos queel progenitor de N ieves es nada menos que M anuel Ignacio Puga, tío de Rosario. Frente a esta laberíntica realidad, tan arraigada en nuestro medio, surgen varios cuestionamientos, sin embargo la primera pregunta que todos los lectores nos hacemos después de conocer estos hechos es por qué se escondió la vida privada de O'Higgins. ¿Sería por ser huacho y dejar una descendencia igual mente de hijos y nietos que crecieron sin la figura paterna? ¿O fue él mismo que quiso silenciar sobre su entorno familiar? No es desproporcionada esta última conjetura si tomamos en cuenta que su madretuvo tres hijos de padres diferentes, en un espacio social rígido y conservador donde el capital social se regía por hipocresías explícitas y la I glesia tenía presencia marcante. Sin duda, era una realidad difícil de administrar para Bernardo. A estos motivos sele suma el no haber reconocido a su único hijo y llegar a enmascararlo al punto de presentarlo en Lima como "su ahijado". Son, éstas, posibles causas que explican el silencio de la historia oficial. Tal vez se pensó que el modelo de padre de la patria, como siempre se nos ha enseñado, no condecía con tales formas de proceder.

Ahora bien, he mencionado el problema del huacho "ilustre" y qué pasa con los miles de niños que crecen sin un padre. En la novela, la mama Candelaria, sabia como todas las mujeres conectadas con la ancestralidad, como dice Jung, sabe perfectamente bien "la mala suerte de los huachos pobres" como es ella y sus propios hijos, a quienes tuvo que dejarlos con su madre. Estando en Lima cuidando a Demetrio y al escuchar a O'Higgins despotricar porque todavía lo llamaban "el Huacho Riquelme", el niño le pregunta a su mama, quiénes son los huachos, "todos nosotros, Demetrio, todos nosotros", le responde Candelaria.

\section{ROSARIO PUGA}

¿Q ué rasgos de carácter tiene la amante de Bernardo y madre de Demetrio? Rosario Puga pertenecía a una prominente familia de patriotas de Concepción quien a los diecinueve años ya estaba separada de su marido, un casamiento arreglado por su padre para despabilarla de un amor con un marinero inglés. Su esposo la despreció -nos afirma el texto- porque sus hijos nacían muertos y con el tiempo él le llenó la casa de huachos que tenía con las inquilinas de su hacienda, y esperaba que Rosario los criara. Con estas palabras se desahoga con su prima $\mathrm{N}$ ieves, algunos años mayor que ella y 
casada con un extranjero. También su matrimonio fue arreglado. En su caso por Bernardo, quien le concertó el matrimonio con Agustín Borne, de nacionalidad irlandesa. En la intimidad de esa conversación, Nieves con toda claridad le confidencia, "¿te das cuenta, Rosario, que por ser huacha a lo sumo podía aspirar a casarme con un extranjero?"

Tanto la hermana Nieves como Rosario son obstinadas y actúan sin miramientos hacia las costumbres desu grupo social. La “querida” deO'Higgins es especialmente rebelde, resuelta, valiente y apasionada - primero de Bernardo y después de un partidario de los Carrera, José Antonio Cotapos-, singularidades inadmisibles por la sociedad criolla en esas primeras décadas del siglo XIX.

El tiempo histórico que rescata la novela correspondeal momento cuando O'H iggins ya es Director Supremo y él, como todas las fuerzas patrióticas, están preocupados en consolidar las ciudades ganadas a los realistas. En esas lides conoce a Rosario y comienzan sus amores. Con el tiempo nace Demetrio. En relación a su vida pública y como Director Supremo, O'H iggins tenía grandes desafíos a enfrentar, preparar la expedición a Perú para acabar con las fuerzas españolas, sumado a la necesidad urgente de organizar un fuerte poderío naval. Además, en la vida privada varios conflictos debían ser superados por la pareja. Lidiar con la enérgica figura femenina que era su madre, quien ejercía fuerteinfluencia en Bernardo y manejar la situación de unión ilegítima.

En relación a Rosario, sus desafíos frente a la sociedad no eran menores. Tenía que conseguir anular su casamiento anterior para que su hijo no fuera un huacho más. Tenía que negociar su lugar, con doña I sabel Riquelme, como la madre del único hijo del Director Supremo. Por otro lado, Rosario le exigía a Bernardo compartir todos los momentos con ella y no dejarla "a la sombra" como le reclamaba. Sin embargo, en varias ocasiones, Rosario tuvo queescuchar recriminaciones como "estás teniendo muchafiguración"...

Con esa urdimbre de hilos delicados, la autora consigue tener un dominio total de las diversas situaciones. El lector se involucra en cada uno delos espacios y se deleita con la fluidez que Juanita Gallardo supo calibrar frente a una compleja situación.

No puedo dejar de mencionar la satisfacción que me dio al Ilegar "Al final" - el último capítulo- dondela autora, al puro estilo Saramago, se confiesa y muestra su modus operandi. "Ahora habla Juanita", nos dice, y nos abre de par en par sus escondites desde los cuales construyó esta narración. La autora explica al gunas triquiñuel as, el la las llama mentiras para que"muchos las reconocieran como tales", y cumplen su objetivo porque le recuerdan a uno que se encuentra en terrenos dominados por la ficción.

Aunque los fueros de la imaginación son ilimitados, yo salté de alegría cuando supeque Josefa, hermana de Rosario, se hacía acompañar, para dis- 
minuir sus penas de amor, con unos "cuentos con que una princesa salvó la vida contándosel os durante más de mil noches a un sultán". Emoción saber que en el recóndito Chile, en una perdida ciudad sureña a comienzos del dieciniueve, ya se leía la recopilación de Antoine Galland de las M il e una noches...

Con este atractivo texto, Juanita Gallardo consigue aproximarnos a Bernardo O'Higgins, ya que la historia lo petrificó en estatuas y nombres de calles. Nos regala un prócer humano, con sus riquezas y debilidades, que sufrió su realidad, sin embargo transmitió a su hijo la misma desdicha de ser huacho, al igual que a miles de chilenos que aún viven la carencia de la figura paterna. Entretenida, documentada y con bellas imágenes es esta novela histórica. 